\title{
Dietary fructose and risk of metabolic syndrome in Chinese residents aged 45 and above: results from the China National Nutrition and Health Survey
}

Shaojie Pang ${ }^{1}$, Pengkun Song ${ }^{2}$, Xueqian Sun ${ }^{3}$, Wentao Qi ${ }^{1 *}$, Chun Yang ${ }^{4}$, Ge Song ${ }^{1}$, Yong Wang ${ }^{1}$ and Jian Zhang ${ }^{2^{*}}$

\begin{abstract}
Background: A growing number of researches supported that dietary fructose was associated with most of the key features of metabolic syndrome (MetS). However, there was no related epidemiological studies among Chinese population, despite the sharp increase in MetS cases. This study explores the relationship between dietary fructose and MetS among Chinese residents aged 45 and above.

Methods: A total of 25,528 participants (11,574 males and 13,954 females) were included in this nationwide representative cross-sectional study of China National Nutrition and Health Survey. Dietary fructose intake was assessed by 3-day 24-h dietary records. MetS was defined by the International Diabetes Federation and Chinese Diabetes Society criteria.

Results: The consumption of dietary fructose was $11.6 \mathrm{~g} /$ day for urban residents and $7.6 \mathrm{~g} /$ day for rural residents. Fruits and vegetables as well as their products were the main sources of fructose intake. There was no association between dietary fructose intake and the odds of having MetS in both urban $(P=0.315)$ and rural residents $(P=0.230)$ after adjustment for confounding factors. Moreover, for urban residents participating physical activities, the odds of having MetS in the fourth quartiles (OR: 0.67; 95\% Cl: 0.52-0.87) was lower than that in the first quartile. In the sensitivity analysis, a significant reduction in the odds of having MetS was also found in the fourth quartiles (OR, $95 \% \mathrm{Cl}: 0.68$, $0.51-0.90 ; 0.67,0.49-0.91 ; 0.74,0.56-0.99)$ compared with the first quartile when excluding smokers, alcohol users, and underweight/obesity, respectively. And there was no association between dietary fructose intake and the odds of having MetS after multivariate adjustment stratified by gender, smoking and alcohol use.
\end{abstract}

Conclusions: Under the current dietary fructose intake status, there was no association between dietary fructose intake and the odds of having MetS among Chinese residents aged 45 and above. Physical activity and relatively low fructose intake may have a beneficial synergistic effect on MetS.

Keywords: Dietary fructose, Metabolic syndrome, Chinese residents, Physical activity

\footnotetext{
*Correspondence: qwt@ags.ac.cn; zhjian6708@aliyun.com ${ }^{1}$ Institute of Grain Quality and Nutrition Research, Academy of National Food and Strategic Reserves Administration, Beijing 100037, People's Republic of China

${ }^{2}$ National Institute for Nutrition and Health, Chinese Center for Disease Control and Prevention, Beijing 100050, People's Republic of China Full list of author information is available at the end of the article
}

\section{Introduction}

Metabolic syndrome (MetS) refers to a series of cardiometabolic risk factors leading to high risk for developing cardiovascular disease, type 2 diabetes, non-alcoholic fatty liver, and chronic kidney disease. Its symptoms 
include abdominal obesity, hyperglycemia, hypertension, and dyslipidemia $[1,2]$. Over the past few decades, the prevalence of MetS has increased dramatically and has become one of the major public-health challenges in China and worldwide [2-4]. The overall standardized prevalence of MetS was $24.2 \%$ among Chinese adults and over $32 \%$ for those who aged 45 and above [5].

Increased sugar intake was widely recognized as a contributor to the worldwide epidemics of obesity, diabetes, and their associated cardio-metabolic risks [6]. Due to its unique set of biochemical, metabolic, and endocrine responses, fructose was usually regarded as the main negative factor in sugars and associated with all the key features of MetS [6, 7]. A series of systematic reviews and meta-analysis discussed the relationship between fructose and components of MetS. Some of them concluded that intakes of fructose were associated with increased risk of obesity, dyslipidemia, hypertension and cardio-metabolic syndrome [8-11]. However, some of them found that a certain dose of fructose had no adverse or even some positive effects on fasting glucose, blood pressure, and blood lipids [12-16]. Most of the studies included in these meta-analyses were interventional studies with high-dose fructose intake. In the "real world" study, a cross-sectional population-based research on Iranians reported that higher consumption of dietary fructose increased the risk of MetS, while no such association was found in the US population $[17,18]$. Differences in dietary intake may be an important reason for the different results. Our previous research found that the average dietary fructose intake of Chinese residents aged 45 and above was $8.29 \mathrm{~g} / \mathrm{d}$, which is lower than that of Americans $(48.07 \mathrm{~g} / \mathrm{d})$ and Iranians $(46.50 \mathrm{~g} / \mathrm{d}$ for male and $37.30 \mathrm{~g} / \mathrm{d}$ for female) [19]. Up to now, there is no large epidemiological study to explore the relationship between dietary fructose and MetS under the current intake level among Chinese population although the prevalence of MetS has increased rapidly.

Based on data of nationally representative cross-sectional survey of China National Nutrition and Health Survey (CNNHS) in 2010-2012, this study aims to investigate the association between dietary fructose intake and MetS among Chinese residents aged 45 and above. Furthermore, we stratified the analysis based on the variables (gender, physical activity, smoking, and alcohol use) that might influence the odds of having MetS.

\section{Materials and method}

\section{Study design and subjects}

The nationwide representative cross-sectional study of CNNHS was conducted between 2010 to 2012 by Chinese Center for Disease Control and Prevention to assess the nutrition and health status of Chinese population. This survey covered all 31 provinces, autonomous regions, and municipalities directly under the Chinese central government (excluding Taiwan, Hong Kong, and Macao). A stratified multistage random cluster sampling method was conducted at 150 surveys sites of 4 types including 34 large cities, 41 small-to-medium cities, 45 general rural areas and 30 poor rural areas. The survey procedure has been described in detail elsewhere [20]. All participants were supposed to undergo three consecutive 24-h dietary records combined with food weighting, survey questionnaires, physical examination, and fasting blood collection.

In this study, we included participants aged 45 and above with complete demographic information, medical history, lifestyle factors and dietary intake data. We excluded those with implausible energy intakes $(<800 \mathrm{kcal} /$ day or $>4800 \mathrm{kcal} /$ day for male and $<500 \mathrm{kcal} /$ day or $>4000 \mathrm{kcal} /$ day for female). Eventually, a total of 25,528 participants $(11,574$ males and 13,954 females) were included [20].

This survey was ethically approved by the Ethical Committee of the National Institute for Nutrition and Food Safety, Chinese Center for Disease Control and Prevention (2013-018). Written informed consent was obtained from all participants.

\section{Data collection and definition}

Data were collected by trained health workers or nurses in health examination centers from local health stations or community clinics according to a standard protocol. Questionnaires including demographic information, medical history, and lifestyle factors, were conducted by trained interviewers. Marital status was categorized into three statues (single, married, divorced/widowed). Education levels were classified into primary schools or below, junior high school, senior high school, and college or above. Smoking was defined as "having smoked 100 cigarettes during lifetime" and "current smoking". Alcohol was referred to as "alcohol intake more than once per month during the past 12 months". Physical activity was defined as "moderate physical activity for more than 10 minutes at least once per week" [21]. According to the grading standards of national residents' net income levels by National Bureau of Statistics in 2009, high income was defined as " $\geq 20000$ per person per year for urban residents or $\geq 10000$ for rural", middle income as " 15000 19999 for urban or $5000 \sim 9999$ for rural", and low income as " $<15000$ for urban or $<5000$ for rural".

Height, weight, waist circumference (WC) and blood pressure (BP) were measured in the morning with standardized procedures. Height was measured in bare feet to the nearest $0.1 \mathrm{~cm}$. Weight was measured in standing position and light clothing to the nearest $0.1 \mathrm{~kg}$. Body 
mass index (BMI) was calculated with weight $(\mathrm{kg})$ being divided by height $(\mathrm{m})$ squared. WC was measured in standing position between the lower edge of the costal arch and the upper edge of the iliac crest. BP levels were measured for 3 times in succession with 1-min interval between the measurements, with a standard mercury sphygmomanometer at the nondominant arm in setting position after $5 \mathrm{~min}$ of rest. Systolic blood pressure (SBP) was measured at the first appearance of a pulse sound (Korotkoff phase 1) and diastolic blood pressure (DBP) at the disappearance of the pulse sound (Korotkoff phase 5). The mean of the three measurements was used for analysis.

\section{Dietary data and assessment of dietary fructose intake}

Data as individual dietary records and household food consumptions were collected over three consecutive days. Individual dietary data including all foods consumed at home and away from home (type, amounts, type of meal, and place of consumption) were collected by trained dietary investigators. Weighting method was used to assess household food consumptions, which included all foods and condiments. The Chinese Food Composition was used to calculate the amount of energy, protein, fat, carbohydrate, and fiber contained in each food consumed by individuals every day.

Since there was no fructose content data in some of the Chinese Food Composition (1460 food items), we used fructose content data of the American Food Composition Database (2183 food items) and Chinese Sugar Content Database in Pre-packaged Foods (363 food items) to assign the value of fructose content for each food item $[22,23]$. The principle of food fructose content assignment was described in detail in our previous study [19].

Total dietary fructose was composed of free-fructose and bound-fructose. Free-fructose intake for each person was calculated from dietary supplement and natural food intake. Bound-fructose intake for each person was calculated by using one-half of dietary total sucrose based on the molecular compositing of sucrose. All forms of fructose including food-fructose and food-sucrose were added to obtain the total fructose intake of each participant based on the food composition database [17].

All foods listed in the food-grouping system used in Chinese Food Composition Table were divided into 13 categories according to the major ingredients: grain and grain products; fruits and fruit products; vegetables and vegetable products; milk and milk products; meat, poultry, fish, and related products; eggs and egg products; legumes and legume products; nuts, seed, and related products; sugars and sweets; nonalcoholic beverages; alcoholic beverages; snacks; and miscellaneous foods.

\section{Anthropomorphic and blood biochemical methods}

Blood samples were collected by trained nurses from all participants undergoing an overnight fast for at least $10 \mathrm{~h}$. Samples were centrifuged at $1500 \mathrm{rpm}$ for $10 \mathrm{~min}$ after being left standing for 30 to $60 \mathrm{~min}$. The centrifuged serum sample were transported to the central laboratory of the National Institute for Nutrition and Health and stored at -80 degrees centigrade. Procedure, processing, and determination for the blood collection were standardized. Fasting plasma glucose (FPG), total cholesterol (TC), high-density lipoprotein cholesterol (HDL-C) and triglycerides (TG) were measured by a Hitachi automatic biochemical analyzer with reagents from Wako Pure Chemical Industries, Ltd. (Tokyo, Japan).

\section{Definition of MetS}

According to the recommendation from the International Diabetes Federation and Chinese Diabetes Society criteria [24, 25], a person who met three or more of the following five criteria were diagnosed as MetS: (1) abdominal obesity (WC $\geq 90 \mathrm{~cm}$ in male or $\geq 85 \mathrm{~cm}$ in female); (2) hyperglycemia (FPG $\geq 6.1 \mathrm{mmol} / \mathrm{L}$ or diagnosed diabetes); (3) hypertension ( $\mathrm{SBP} \geq 130 \mathrm{mmHg}$ or $\mathrm{DBP} \geq 85 \mathrm{mmHg}$ or diagnosed hypertension); (4) $\mathrm{TG} \geq 1.70 \mathrm{mmol} / \mathrm{L} ;$ (5) HDL-C $<1.04 \mathrm{mmol} / \mathrm{L}$.

\section{Statistical analysis}

Data were collected with specialized software. Data cleaning and statistical analyses were performed by using SAS version 9.4 (SAS Institute Inc., Cary, NC, USA). Due to the differences of total dietary fructose intake and the prevalence of MetS between urban and rural areas, analyses were performed separately in regard with urban and rural samples. Categorical variables were presented as percentage and examined with a chi-square test. Continuous variables with normal distribution were presented as mean $(95 \% \mathrm{CI})$ and were compared across groups with $\mathrm{z}$ test. Skewed distribution variables were indicated with quartiles and were examined by non-parametric statistical hypothesis test. The Cochran and Mantel-Haenszel test were used to analyze the characteristics of normal and MetS in urban and rural areas. Univariate and multivariableadjusted logistic regression were performed to explore the association between dietary fructose intake and risk of MetS. The first quartile of total dietary fructose intake was set as the reference. Three models were involved in this study: model 1 did not adjust any variables; model 2 adjusted for gender, age, education, marital status, smoking, alcohol, physical activity, income, energy, protein, fat, carbohydrate, fiber, and TC; model 
3 adjusted for all variables in model 2 plus BMI. Odds ratios (OR) and 95\%CI were measured. A value of $P<0.05$ was considered statistically significant.

\section{Results}

\section{Basic characteristics of the study population}

A total of 25,528 participants were included in the study with an average age of 59.1 years old in which 13,067 (44.1\% males) were urban residents and 12,461 $(46.6 \%$ males $)$ were rural residents. And significant differences were found between urban and rural participants regarding age, gender, marital status, education, smoking, alcohol, physical activity, and income. BMI, WC, TC, TG, and FPG were higher in urban participants than that in rural participants $(P<0.001)$, whereas HDL-C was the opposite $(P<0.001$, Table 1$)$. Table 2 showed that the prevalence of MetS in urban areas was $32.4 \%$ which was higher than that in rural with $24.7 \%(P<0.001)$.

Table 1 Basic characteristics of the study population in urban and rural

\begin{tabular}{|c|c|c|c|c|}
\hline & Total & Urban & Rural & $p$-Value \\
\hline $\mathrm{N}$ & 25,528 & 13,067 & 12,461 & \\
\hline Age, years & $59.1(59.0,59.2)$ & $59.7(59.5,59.8)$ & $58.5(58.3,58.7)$ & $<0.001$ \\
\hline \multicolumn{5}{|l|}{ Gender, n (\%) } \\
\hline Male & $11,574(45.3)$ & $5762(44.1)$ & $5812(46.6)$ & \\
\hline Female & $13,954(54.7)$ & 7305 (55.9) & $6649(53.4)$ & \\
\hline Marital status, n (\%) & & & & 0.011 \\
\hline Single & $181(0.7)$ & $84(0.6)$ & $97(0.8)$ & \\
\hline Married & $23,093(90.5)$ & $11,767(90.1)$ & $11,326(90.9)$ & \\
\hline Divorced or Widowed & $2254(8.8)$ & $1216(9.3)$ & $1038(8.3)$ & \\
\hline Education, n (\%) & & & & $<0.001$ \\
\hline Primary schools or below & $12,407(48.6)$ & $4426(33.9)$ & $7981(64.1)$ & \\
\hline Junior high school & $7980(31.3)$ & $4556(34.9)$ & $3424(27.5)$ & \\
\hline Senior high school & $3963(15.5)$ & $2975(22.8)$ & $988(7.9)$ & \\
\hline College or above & $1178(4.6)$ & $1110(8.5)$ & $68(0.6)$ & \\
\hline Smoking, n (\%) & & & & $<0.001$ \\
\hline Ever/Never & $6830(26.8)$ & 3065 (23.5) & $3765(30.2)$ & \\
\hline Current & $18,698(73.2)$ & $10,002(76.5)$ & $8696(69.8)$ & \\
\hline Alcohol, n (\%) & & & & $<0.001$ \\
\hline Ever/Never & $8169(32.0)$ & $4189(32.1)$ & 3980 (31.9) & \\
\hline Current & $17,359(68.0)$ & 8878 (67.9) & $8481(68.1)$ & \\
\hline Physical activity, n (\%) & & & & $<0.001$ \\
\hline Yes & $4012(15.7)$ & $3309(25.3)$ & $703(5.6)$ & \\
\hline No & $21,516(84.3)$ & $9758(74.7)$ & $11,758(94.4)$ & \\
\hline Income, n (\%) & & & & $<0.001$ \\
\hline Low & $11,940(46.8)$ & 7024 (53.8) & 4916 (39.5) & \\
\hline Middle & $5202(20.4)$ & $1833(14.0)$ & $3369(27.0)$ & \\
\hline High & $7276(28.5)$ & $3456(26.5)$ & $3820(30.7)$ & \\
\hline Unanswered & $1110(4.4)$ & $754(5.8)$ & $356(2.9)$ & \\
\hline $\mathrm{BMI}, \mathrm{kg} / \mathrm{m}^{2}$ & $24.1(24.1,24.2)$ & $24.6(24.6,24.7)$ & $23.6(23.6,23.7)$ & $<0.001$ \\
\hline $\mathrm{WC}, \mathrm{cm}$ & $82.9(82.7,83.0)$ & $84.2(84.0,84.3)$ & $81.5(81.3,81.6)$ & $<0.001$ \\
\hline $\mathrm{SBP}, \mathrm{mmHg}$ & $130.9(130.6,131.1)$ & $130.7(130.4,131.1)$ & $131.0(130.6,131.4)$ & 0.640 \\
\hline $\mathrm{DBP}, \mathrm{mmHg}$ & $81.0(80.8,81.1)$ & $80.9(80.7,81.1)$ & $81.1(81.9,81.3)$ & 0.929 \\
\hline $\mathrm{TC}, \mathrm{mmol} / \mathrm{L}$ & $4.79(4.78,4.80)$ & $4.89(4.87,4.90)$ & $4.70(4.68,4.72)$ & $<0.001$ \\
\hline $\mathrm{HDL}-\mathrm{C}, \mathrm{mmol} / \mathrm{L}$ & $1.19(1.19,1.20)$ & $1.18(1.18,1.19)$ & $1.20(1.20,1.21)$ & $<0.001$ \\
\hline $\mathrm{TG}, \mathrm{mmol} / \mathrm{L}$ & $1.50(1.49,1.51)$ & $1.55(1.53,1.57)$ & $1.44(1.42,1.46)$ & $<0.001$ \\
\hline $\mathrm{FPG}, \mathrm{mmol} / \mathrm{L}$ & $5.52(5.50,5.54)$ & $5.67(5.64,5.69)$ & $5.36(5.34,5.39)$ & $<0.001$ \\
\hline
\end{tabular}

Mean value (95\% confidence interval) or $\mathrm{n}(\%)$ were shown; $B M I$ body mass index, WC waist circumference, SBP systolic blood pressure, DBP diastolic blood pressure, $T C$ total cholesterol, HDL-C high-density lipoprotein cholesterol, $T G$ triglyceride, FPG fasting plasma glucose 
Table 2 Basic characteristics of normal and MetS in urban and rural

\begin{tabular}{|c|c|c|c|c|c|}
\hline & \multicolumn{2}{|l|}{ Urban } & \multicolumn{2}{|l|}{ Rural } & \multirow[t]{2}{*}{$p$-Value } \\
\hline & Normal & MetS & Normal & MetS & \\
\hline Case, n (\%) & $8830(67.6)$ & $4237(32.4)$ & $9388(75.3)$ & $3073(24.7)$ & $<0.001$ \\
\hline Age, n (\%) & & & & & $<0.001$ \\
\hline $45-59$ years & $5078(57.5)$ & $2004(47.3)$ & $5598(59.6)$ & $1702(55.4)$ & \\
\hline 60-74years & $3353(38.0)$ & $1997(47.1)$ & $3420(36.4)$ & $1247(40.6)$ & \\
\hline 75-years & $399(4.5)$ & $236(5.6)$ & $370(3.9)$ & $124(4.0)$ & \\
\hline Gender, n (\%) & & & & & 0.248 \\
\hline Male & $3788(42.9)$ & $1974(46.6)$ & $4526(48.2)$ & $1286(41.9)$ & \\
\hline Female & $5042(57.1)$ & $2263(53.4)$ & $4862(51.8)$ & $1787(58.2)$ & \\
\hline Marital status, n (\%) & & & & & 0.246 \\
\hline Single & $63(0.7)$ & $21(0.5)$ & $88(0.9)$ & $9(0.3)$ & \\
\hline Married & $7956(90.1)$ & $3811(90.0)$ & $5811(90.7)$ & 2815 (91.6) & \\
\hline Divorced or Widowed & $811(9.2)$ & 405 (9.6) & $789(8.4)$ & $249(8.1)$ & \\
\hline Education, n (\%) & & & & & $<0.001$ \\
\hline Primary schools or below & $3022(34.2)$ & $1404(33.1)$ & $6092(64.9)$ & $1889(61.5)$ & \\
\hline Junior high school & $3062(34.7)$ & $1494(35.3)$ & $2546(27.1)$ & $878(28.6)$ & \\
\hline Senior high school & $2035(23.1)$ & $940(22.2)$ & $709(7.6)$ & $279(9.1)$ & \\
\hline College or above & $711(8.1)$ & $399(9.4)$ & $41(0.4)$ & $27(0.9)$ & \\
\hline Smoking, n (\%) & & & & & $<0.001$ \\
\hline Ever/Never & $6725(76.2)$ & $3277(77.3)$ & $6248(66.6)$ & $2233(72.7)$ & \\
\hline Current & 2105 (23.8) & $960(22.7)$ & $3140(33.4)$ & $840(27.3)$ & \\
\hline Alcohol, n (\%) & & & & & $<0.001$ \\
\hline Ever/Never & $5926(67.1)$ & $2952(69.7)$ & $6374(67.9)$ & $2322(75.6)$ & \\
\hline Current & 2904 (32.9) & $1285(30.3)$ & 3014 (32.1) & $751(24.4)$ & \\
\hline Physical activity, n (\%) & & & & & $<0.001$ \\
\hline Yes & $2149(24.3)$ & $1160(27.4)$ & $460(4.9)$ & $243(7.9)$ & \\
\hline No & $6681(75.7)$ & 3077 (72.6) & 8928 (95.1) & $2830(92.1)$ & \\
\hline Income, n (\%) & & & & & 0.004 \\
\hline Low & $4835(54.8)$ & $2189(51.7)$ & 3713 (39.6) & $1203(39.2)$ & \\
\hline Middle & $1195(13.5)$ & $638(15.1)$ & 2594 (27.6) & $775(25.2)$ & \\
\hline High & $2273(25.7)$ & $1183(27.9)$ & $2819(30.0)$ & $1001(32.6)$ & \\
\hline Unanswered & $527(6.0)$ & $227(5.4)$ & $262(2.8)$ & $94(3.1)$ & \\
\hline
\end{tabular}

Table 3 Intake status of dietary fructose and nutrients in urban and rural residents

\begin{tabular}{|c|c|c|c|c|c|c|c|c|c|}
\hline & \multicolumn{4}{|l|}{ City } & \multicolumn{4}{|l|}{ Rural } & \multirow[t]{2}{*}{$p$-Value } \\
\hline & Mean & $P_{25 \text { th }}$ & Median & $P_{75 \text { th }}$ & Mean & $P_{25 \text { th }}$ & Median & $P_{75 \text { th }}$ & \\
\hline Total Fructose, g/d & 11.6 & 4.8 & 8.3 & 14.5 & 7.6 & 3.4 & 5.3 & 8.8 & $<0.001$ \\
\hline Free-Fructose, g/d & 6.7 & 2.2 & 4.2 & 8.4 & 4.6 & 1.6 & 2.7 & 5.1 & $<0.001$ \\
\hline Bound-Fructose, g/d & 4.9 & 2.4 & 3.7 & 6.0 & 3.1 & 1.6 & 2.4 & 3.7 & $<0.001$ \\
\hline Energy, kcal/d & 1887 & 1454 & 1780 & 2204 & 2159 & 1648 & 2041 & 2547 & $<0.001$ \\
\hline Protein, g/d & 61.2 & 44.8 & 56.6 & 72.5 & 59.3 & 43.6 & 55.4 & 71.2 & $<0.001$ \\
\hline Fat, g/d & 76.1 & 50.2 & 69.2 & 94.1 & 70.8 & 44.0 & 64.0 & 90.2 & $<0.001$ \\
\hline Carbohydrate, g/d & 240.3 & 178.0 & 224.9 & 284.3 & 322.7 & 238.7 & 299.4 & 378.7 & $<0.001$ \\
\hline Fiber, g/d & 10.7 & 6.7 & 9.2 & 12.9 & 10.5 & 6.7 & 9.2 & 12.5 & 0.957 \\
\hline
\end{tabular}




\section{Dietary fructose intake level and food sources}

Table 3 shows the basic characteristics of dietary fructose and nutrients with mean and quartiles. The average daily total dietary fructose intake for urban residents was $11.6 \mathrm{~g}$ and $7.6 \mathrm{~g}$ for rural residents. Total dietary fructose intake level was significantly higher in urban residents than that in rural residents, including both free-fructose and bound-fructose levels $(P<0.001)$. Protein and fat intake were significantly higher in urban residents while energy and carbohydrate were higher in rural residents $(P<0.001)$.

We further investigated the food sources of dietary fructose. Fruits and fruit products, vegetables and vegetable products, and snacks were the top three food sources for dietary fructose among urban residents accounting $69.02 \%$ for the total dietary fructose intake, while vegetables and vegetable products, Fruits and fruit products, and grain and grain products were the top three food sources for dietary fructose in rural residents contributing $73.45 \%$ to the total dietary fructose intake (Fig. 1). Food sources of total dietary fructose in urban and rural areas with mean and quartiles were shown in Table S1.

\section{The association between dietary fructose intake and the odds of having MetS}

For urban residents, in addition to FPG, there were significant differences in WC, SBP, DBP, TG and HDL-C between the quartiles. The prevalence of MetS was higher in the third quartile than that in the first and forth quartiles $(P<0.05)$. For rural residents, we found significant differences in FPG, SBP, DBP, TG, and HDL-C between the quartiles except for WC. There was no significant difference in the prevalence of MetS between quartiles (Table 4).

Compared with the first quartile, the odds of MetS was higher in the third quartile among urban residents (OR: 1.13; 95\%CI: 1.02-1.26). After adjusting confounding factors (gender, age, education, marital status, smoking, alcohol, physical activity, income, energy, protein, fat, carbohydrate, TC and BMI), no statistical significance was found. For rural residents, regardless of adjustments made for confounding factors, no association between dietary fructose intake and the odds of having MetS was found (Table 5).

\section{Stratified analysis of the association between dietary fructose intake and risk of MetS}

We further analyzed the association between dietary fructose intake and the odds of having MetS stratified by gender, physical activity, smoking, and alcohol use. For urban residents with physical activities, the prevalence and the odds of MetS were both lower with the increase of the quartile levels of dietary fructose intake $(P<0.001)$. Compared with the first quartile, the odds of having MetS in the fourth quartile (OR: 0.67 ; 95\%CI: 0.52-0.87) was lower after adjustment for confounding factors (Table 6). In the sensitivity analysis, we also found a significant reduction in the odds of having MetS in the fourth quartile (OR, 95\%CI: 0.68, 0.51-0.90; 0.67, 0.49-0.91; 0.74, 0.56-0.99) compared with the first quartile when excluding smokers, alcohol users, and $\mathrm{BMI}<18.5$ or $\mathrm{BMI} \geq 28$, respectively (Table 7). For urban residents with no physical activities, the prevalence of MetS increased with the increase of dietary fructose intake $(P=0.008)$. There was

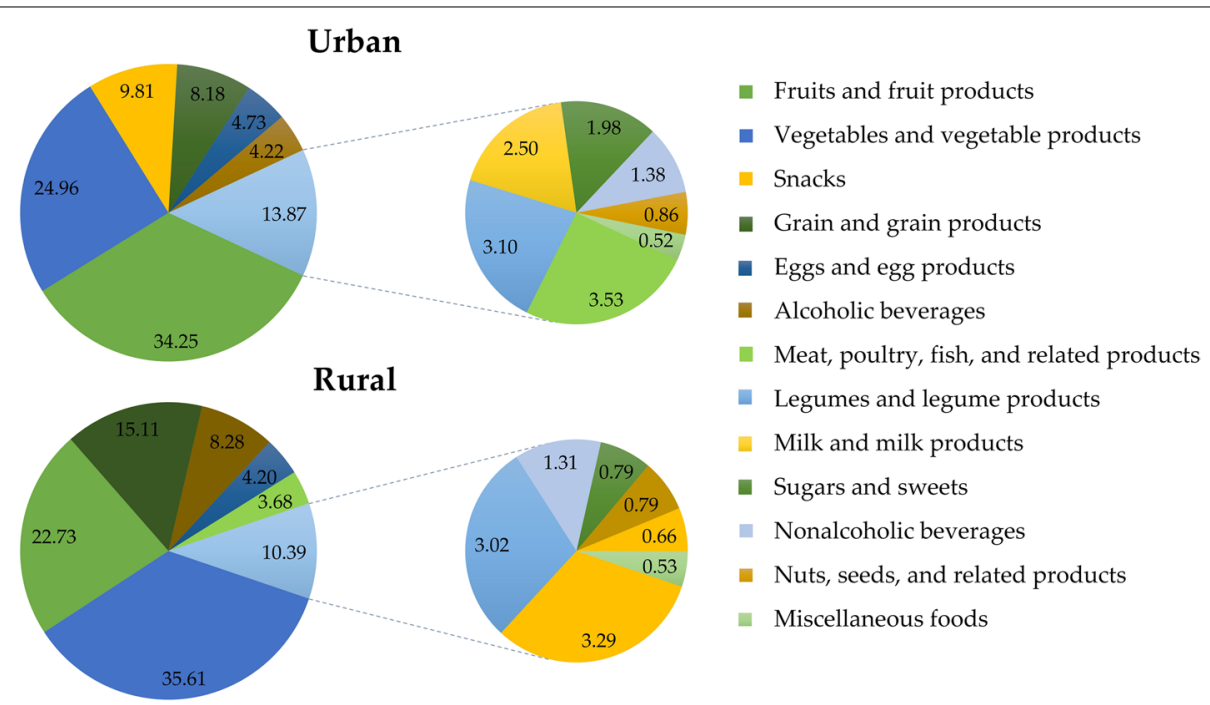

Fig. 1 Distribution of dietary fructose from various foods in urban and rural residents. The smaller circle represents a part of the larger circle. The proportion of small circle in great circle for urban was 13.87 and $10.39 \%$ for rural 
Table 4 Basic characteristics of components of MetS by the quartiles of dietary fructose intake

\begin{tabular}{|c|c|c|c|c|c|}
\hline & Q1 & Q2 & Q3 & Q4 & $p$-Value \\
\hline Urban & 3266 & 3268 & 3266 & 3267 & \\
\hline Dietary fructose & $3.4(3.4,3.4)$ & $6.4(6.4,6.4)$ & $11.1(11.1,11.1)$ & $25.6(25.1,26.2)$ & \\
\hline$W C, \mathrm{~cm}$ & $83.5(83.2,83.8)$ & $84.5(84.1,84.8)^{1}$ & $84.4(84.1,84.8)^{1}$ & $84.3(83.9,84.6)^{1}$ & $<0.001$ \\
\hline $\mathrm{FPG}, \mathrm{mmol} / \mathrm{L}$ & $5.68(5.63,5.73)$ & $5.72(5.67,5.78)$ & $5.64(5.59,5.69)$ & $5.62(5.57,5.67)$ & 0.081 \\
\hline $\mathrm{SBP}, \mathrm{mmHg}$ & $131.8(131.1,132.5)$ & $132.0(131.3,132.7)$ & $130.3(129.7,131.0)^{1,2}$ & $128.8(128.2,129.4)^{1-3}$ & $<0.001$ \\
\hline $\mathrm{DBP}, \mathrm{mmHg}$ & $81.0(80.6,81.4)$ & $81.5(81.2,81.9)$ & $80.8(80.5,81.2)$ & $80.2(79.9,80.6)^{1,2}$ & $<0.001$ \\
\hline $\mathrm{TG}, \mathrm{mmol} / \mathrm{L}$ & $1.49(1.46,1.53)$ & $1.56(1.53,1.60)^{1}$ & $1.59(1.55,1.62)^{1}$ & $1.56(1.53,1.60)$ & 0.002 \\
\hline $\mathrm{HDL}-\mathrm{C}, \mathrm{mmol} / \mathrm{L}$ & $1.20(1.19,1.22)$ & $1.19(1.18,1.20)$ & $1.18(1.16,1.18)^{1}$ & $1.17(1.16,1.18)^{1}$ & $<0.000$ \\
\hline MetS, n (\%) & $1019(31.2)$ & $1083(33.1)$ & $1109(34.0)^{1}$ & $1027(31.4)^{3}$ & 0.048 \\
\hline Rural & 3115 & 3116 & 3115 & 3115 & \\
\hline Dietary fructose & $2.5(2.5,2.5)$ & $4.3(4.3,4.3)$ & $6.8(6.8,6.8)$ & $16.8(16.4,17.2)$ & \\
\hline$W C, \mathrm{~cm}$ & $81.1(80.7,81.4)$ & $81.5(81.1,81.8)$ & $81.7(81.3,82.1)$ & $81.6(81.3,81.9)$ & 0.087 \\
\hline $\mathrm{FPG}, \mathrm{mmol} / \mathrm{L}$ & $5.37(5.32,5.42)$ & $5.44(5.39,5.49)$ & $5.32(5.28,5.37)^{2}$ & $5.32(5.27,5.37)^{2}$ & 0.001 \\
\hline $\mathrm{SBP}, \mathrm{mmHg}$ & $132.6(131.9,133.4)$ & $131.2(130.5,131.9)^{1}$ & $130.9(130.2,131.7)^{1}$ & $129.3(128.5,130.0)^{1-3}$ & $<0.001$ \\
\hline $\mathrm{DBP}, \mathrm{mmHg}$ & $81.6(81.2,82.0)$ & $81.0(80.6,81.4)$ & $81.0(80.6,81.4)$ & $80.7(80.3,81.1)^{1}$ & 0.017 \\
\hline $\mathrm{TG}, \mathrm{mmol} / \mathrm{L}$ & $1.39(1.35,1.42)$ & $1.43(1.39,1.47)$ & $1.43(1.39,1.47)$ & $1.52(1.48,1.57)^{1-3}$ & $<0.001$ \\
\hline $\mathrm{HDL}-\mathrm{C}, \mathrm{mmol} / \mathrm{L}$ & $1.22(1.21,1.24)$ & $1.22(1.21,1.23)$ & $1.20(1.18,1.21)^{1,2}$ & $1.18(1.16,1.19)^{1,2}$ & $<0.001$ \\
\hline MetS, n (\%) & $764(24.5)$ & $772(24.8)$ & $805(25.8)$ & $732(23.5)$ & 0.199 \\
\hline
\end{tabular}

${ }^{1}$ : compared with Q1, $p<0.05^{2} ;:$ compared with Q2, $p<0.05^{3} ;:$ compared with $\mathrm{Q} 3, p<0.05$

Table 5 The association between dietary fructose intake and the odds of having MetS

\begin{tabular}{|c|c|c|c|c|c|}
\hline & \multicolumn{4}{|c|}{ Dietary fructose intake } & \multirow[t]{2}{*}{$p$-Value } \\
\hline & Q1 & Q2 & Q3 & Q4 & \\
\hline \multicolumn{6}{|l|}{ Urban } \\
\hline Model 1 & 1.00 & $\begin{array}{l}1.09(0.98 \\
1.21)\end{array}$ & $\begin{array}{l}1.13(1.02, \\
1.26)\end{array}$ & $\begin{array}{l}1.01(0.91 \\
1.12)\end{array}$ & 0.048 \\
\hline Model 2 & 1.00 & $\begin{array}{l}1.08(0.97, \\
1.20)\end{array}$ & $\begin{array}{l}1.10(0.99 \\
1.23)\end{array}$ & $\begin{array}{l}0.97(0.86 \\
1.09)\end{array}$ & 0.058 \\
\hline Model 3 & 1.00 & $\begin{array}{l}1.03(0.92, \\
1.17)\end{array}$ & $\begin{array}{l}1.08(0.96 \\
1.22)\end{array}$ & $\begin{array}{l}0.97(0.85 \\
1.11)\end{array}$ & 0.336 \\
\hline \multicolumn{6}{|l|}{ Rural } \\
\hline Model 1 & 1.00 & $\begin{array}{l}1.01(0.90, \\
1.14)\end{array}$ & $\begin{array}{l}1.07(0.96 \\
1.20)\end{array}$ & $\begin{array}{l}0.95(0.84 \\
1.06)\end{array}$ & 0.199 \\
\hline Model 2 & 1.00 & $\begin{array}{l}1.03(0.92, \\
1.16)\end{array}$ & $\begin{array}{l}1.13(1.00 \\
1.27)\end{array}$ & $\begin{array}{l}1.03(0.90 \\
1.17)\end{array}$ & 0.213 \\
\hline Model 3 & 1.00 & $\begin{array}{l}1.03(0.90 \\
1.18)\end{array}$ & $\begin{array}{l}1.14(0.99 \\
1.31)\end{array}$ & $\begin{array}{l}1.03(0.89 \\
1.19)\end{array}$ & 0.246 \\
\hline
\end{tabular}

Model 1: crude; Model 2: adjusted gender, age, education, marital status, smoking, alcohol, physical activity, income, energy, protein, fat, carbohydrate, fiber, TC; Model 3: model 2 plus BMI

no significant difference for the relationship between dietary fructose intake and the odds of having MetS after multivariate adjustment, as was the case in the sensitivity analysis (Tables 6, 7).

There was no association between dietary fructose intake and the odds of having MetS for rural residents regardless of physical activities (Table S2). When stratified by gender, the prevalence of MetS was the lowest in the first quartile of dietary fructose intake for urban males, but in the fourth quartile for urban females (Table S3). And there was no association between dietary fructose intake and the odds of having MetS after multivariate adjustment stratified by gender, smoking and alcohol (Tables S3, S4, S5).

\section{Discussion}

In this nationwide representative cross-sectional study, we discussed the association between dietary fructose intake and the odds of having MetS among Chinese residents aged 45 and above. The consumption of dietary fructose for urban residents was $11.6 \mathrm{~g} /$ day and for rural residents was $7.6 \mathrm{~g} /$ day. Under the current dietary fructose intake status, we did not find associations between dietary fructose intake and the odds of having MetS in both urban and rural residents. However, there was a significant inverse association between dietary fructose intake and MetS for urban residents with physical activities.

A large number of researches suggested that fructose was a culprit in the occurrence of MetS through several metabolic pathways, such as increasing hepatic de novo lipogenesis in the liver [26], depleting ATP stores which results in increasing generation of uric acid via purine pathway $[27,28]$, affecting on plasma lipids, lipoprotein, and apolipoproteins [29,30], and interacting with hostgastrointestinal microbe interactions [31, 32]. However, 
Table 6 Stratified analysis of the association between dietary fructose intake and the odds of having MetS by physical activity in urban residents

\begin{tabular}{|c|c|c|c|c|c|}
\hline & \multicolumn{4}{|c|}{ Dietary fructose intake } & \multirow[t]{2}{*}{$p$-Value } \\
\hline & Q1 & Q2 & Q3 & Q4 & \\
\hline \multicolumn{6}{|l|}{ Physical activity } \\
\hline MetS, n (\%) & $233(42.1)$ & $236(36.2)$ & $324(35.9)$ & $367(30.6)$ & $<0.001$ \\
\hline Model 1 & 1.00 & $0.78(0.62,0.99)$ & $0.77(0.62,0.96)$ & $0.61(0.49,0.75)$ & $<0.001$ \\
\hline Model 2 & 1.00 & $0.79(0.62,1.00)$ & $0.79(0.63,0.99)$ & $0.63(0.50,0.80)$ & 0.002 \\
\hline Model 3 & 1.00 & $0.79(0.61,1.03)$ & $0.82(0.63,1.05)$ & $0.67(0.52,0.87)$ & 0.026 \\
\hline \multicolumn{6}{|c|}{ Non-physical activity } \\
\hline MetS, n (\%) & $786(29.0)$ & $846(32.3)$ & $785(33.2)$ & $660(32.0)$ & 0.007 \\
\hline Model 1 & 1.00 & $1.17(1.04,1.32)$ & $1.22(1.08,1.37)$ & $1.15(1.02,1.30)$ & 0.007 \\
\hline Model 2 & 1.00 & $1.15(1.02,1.30)$ & $1.18(1.04,1.34)$ & $1.09(0.95,1.26)$ & 0.046 \\
\hline Model 3 & 1.00 & $1.11(0.97,1.27)$ & $1.15(1.00,1.33)$ & $1.09(0.93,1.27)$ & 0.252 \\
\hline
\end{tabular}
BMI

Table 7 Sensitivity analysis of the association between dietary fructose intake and the odds of having MetS by physical activity in urban residents

\begin{tabular}{|c|c|c|c|c|c|}
\hline & \multicolumn{4}{|c|}{ Dietary fructose intake } & \multirow[t]{2}{*}{$p$-Value } \\
\hline & Q1 & Q2 & Q3 & Q4 & \\
\hline \multicolumn{6}{|l|}{ Physical activity } \\
\hline MetS, n (\%) & $188(41.3)$ & $185(34.9)$ & $256(35.1)$ & $313(30.1)$ & $<0.001$ \\
\hline Model $1^{\text {a }}$ & 1.00 & $0.76(0.59,0.99)$ & $0.77(0.60,0.98)$ & $0.61(0.49,0.77)$ & $<0.001$ \\
\hline Model $2^{\mathrm{a}}$ & 1.00 & $0.77(0.59,1.01)$ & $0.78(0.60,1.00)$ & $0.62(0.48,0.80)$ & 0.004 \\
\hline Model $3^{\mathrm{a}}$ & 1.00 & $0.77(0.57,1.03)$ & $0.82(0.62,1.08)$ & $0.68(0.51,0.90)$ & 0.042 \\
\hline MetS, n (\%) & $168(42.5)$ & $166(37.8)$ & $207(34.2)$ & $230(30.1)$ & $<0.001$ \\
\hline Model $1^{\mathrm{b}}$ & 1.00 & $0.82(0.62,1.08)$ & $0.70(0.54,0.91)$ & $0.58(0.45,0.75)$ & $<0.001$ \\
\hline Model $2^{b}$ & 1.00 & $0.84(0.63,1.11)$ & $0.71(0.54,0.93)$ & $0.59(0.44,0.78)$ & 0.002 \\
\hline Model $3^{b}$ & 1.00 & $0.87(0.64,1.19)$ & $0.76(0.56,1.00)$ & $0.67(0.49,0.91)$ & 0.043 \\
\hline MetS, n (\%) & $147(33.2)$ & $166(30.8)$ & $234(31.0)$ & $268(26.0)$ & 0.017 \\
\hline Model $1^{c}$ & 1.00 & $0.90(0.69,1.17)$ & $0.90(0.70,1.16)$ & $0.71(0.56,0.90)$ & 0.017 \\
\hline Model $2^{c}$ & 1.00 & $0.84(0.63,1.11)$ & $0.71(0.54,0.93)$ & $0.59(0.44,0.78)$ & 0.002 \\
\hline Model $3^{c}$ & 1.00 & $0.89(0.66,1.20)$ & $0.92(0.70,1.23)$ & $0.74(0.56,0.99)$ & 0.151 \\
\hline \multicolumn{6}{|c|}{ Non- physical activity } \\
\hline MetS, n (\%) & $602(29.6)$ & $650(34.36)$ & $590(33.50)$ & 493 (31.58) & 0.008 \\
\hline Model $1^{\mathrm{a}}$ & 1.00 & $1.25(1.09,1.42)$ & $1.20(1.05,1.38)$ & $1.10(0.95,1.27)$ & 0.008 \\
\hline Model $2^{\mathrm{a}}$ & 1.00 & $1.22(1.06,1.40)$ & $1.17(1.01,1.35)$ & $1.06(0.90,1.24)$ & 0.021 \\
\hline Model $3^{\mathrm{a}}$ & 1.00 & $1.15(0.99,1.35)$ & $1.15(0.98,1.35)$ & $1.07(0.89,1.28)$ & 0.223 \\
\hline MetS, n (\%) & $602(31.1)$ & $620(34.0)$ & $542(33.8)$ & $417(31.8)$ & 0.182 \\
\hline Model $1^{b}$ & 1.00 & $1.14(0.99,1.31)$ & $1.13(0.98,1.30)$ & $1.03(0.89,1.20)$ & 0.182 \\
\hline Model $2^{b}$ & 1.00 & $1.12(0.97,1.29)$ & $1.09(0.94,1.27)$ & $0.98(0.83,1.16)$ & 0.221 \\
\hline Model $3^{b}$ & 1.00 & $1.07(0.92,1.25)$ & $1.05(0.89,1.25)$ & $0.95(0.78,1.15)$ & 0.503 \\
\hline MetS, n (\%) & $541(24.3)$ & $572(27.0)$ & $534(27.6)$ & $450(26.3)$ & 0.073 \\
\hline Model $1^{c}$ & 1.00 & $1.16(1.01,1.33)$ & $1.19(1.03,1.37)$ & $1.12(0.97,1.29)$ & 0.073 \\
\hline Model $2^{c}$ & 1.00 & $1.12(0.97,1.29)$ & $1.09(0.94,1.27)$ & $0.98(0.83,1.16)$ & 0.221 \\
\hline Model $3^{c}$ & 1.00 & $1.12(0.96,1.31)$ & $1.14(0.97,1.33)$ & $1.06(0.89,1.26)$ & 0.354 \\
\hline
\end{tabular}

Model 1: crude; Model 2: adjusted gender, age, education, marital status, smoking, alcohol, income, energy, protein, fat, carbohydrate, fiber, TC; Model 3: model 2 plus BMI. ${ }^{\text {a excluded smokers; }}{ }^{\mathrm{b}}$ excluded alcohol; ${ }^{\mathrm{c}}$ excluded $\mathrm{BMI}<18.5$, and $\mathrm{BMI} \geq 28$ 
there were still disputes between mechanism studies and population epidemiological studies. According to the systematic reviews and meta-analysis, high doses of fructose $(\geq 100 \mathrm{~g} /$ day) increased serum TG concentration [10, 33], low to middle doses of fructose $(0 \sim 90 \mathrm{~g} /$ day $)$ had a benefit effect in HbA1c [14, 34]. But fructose did not increase the risk of hypertension and type 2 diabetes [13, 35], also, it did not affect serum HDL-C concentration [33] and cause weight gain when it replaced other carbohydrate in diets to provide similar calories [36].

In present study, we did not find an association between dietary fructose intake and the odds of having MetS among Chinese residents aged 45 and above. The results of this study were consistent to the study from the NHANES 1999-2006 which showed that ordinary fructose consumption (approximately 37\% of total sugars and $9 \%$ of daily energy in the US population) had no association with the odds of having MetS [18]. Both of the two studies were population-based cross-sectional studies. However, a systematic review and meta-analysis discussing the association of fructose consumption and components of MetS reported that fructose consumption was positively associated with FPG, TG and SBP, and negatively associated with HDL-C [9]. We assumed several reasons for the difference. On the one hand, the fructose sources were different. Food sources of fructose in this meta-analysis were from industrialized foods. In our study, however, fruits and fruit products, vegetables and vegetable products were the most dominant food sources, accounting for more than $50 \%$ of dietary fructose. One study reported that most food sources of dietary fructose (especially fruits) did not have a harmful effect on indicators of health (HbA1c, fasting insulin), but several food sources of fructose (especially sugarssweetened beverages) adding excessive energy to diets showed negative effects [37]. On the other hand, the fructose intake was different. Fructose provided at least 15\% of daily energy requirements in the 15 studies included in this meta-analysis. In our study, however, the average dietary fructose intakes for urban and rural residents was $11.6 \mathrm{~g} /$ day and $7.6 \mathrm{~g} /$ day, respectively. They contributed less than $3 \%$ of energy requirements. Several systematic reviews reported that a continuous exposure to high fructose intake may have adverse health effects [38, 39]. The previous study has shown that the percentage of total calories from added sugar containing food of Chinese residents in 2010-2010 was $9.09 \%$, which was under the recommended limits (10\%) of WHO [40, 41]. In addition, some researchers argued that the before-after design used by the authors, the lack of adjustment for energy as an important confounding variable, and unclear statistical methods all of these render their results as uninterpretable. Under calorie-matched conditions, this systematic review and meta-analysis cannot infer that fructose uniquely affects most components of MetS [42]. In this study, we not only adjusted the confounding factors, including energy, but also stratified analyzed the variables (gender, physical activity, smoking, and alcohol use) that might influence the odds of having MetS.

Interestingly, we found that the odds of MetS was lower with the increase of the quartile levels of dietary fructose intake for the urban residents with physical activities. In recent years, a growing number of researches supported the idea that physical activities might play a role of modulator for fructose's health effects $[38,39$, 43-45]. Fructose was generally processed in splanchnic organs (small bowel, liver, kidneys) and turned into glucose, lactate, and fatty acids, which serve as metabolic energy substrates in extra-splanchnic organs and tissues [38]. As fructose uptake and fructolysis were unregulated processes, the amount of metabolic energy substrates was proportionate to fructose intake [43]. For sedentary subjects, high fructose intake caused an overflow of metabolic energy substrates which resulted in increased gluconeogenesis, de novo lipogenesis, and triglyceriderich lipoprotein secretion in the liver [43]. In contrast, for physically active subjects, a high fructose intake will be accompanied with high energy expenditure, in this way fructose would be mainly metabolized into glucose and lactate which can be readily oxidized to support ATP synthesis and result in a net lactate release from splanchnic organs (mostly the liver) to the working muscle [43]. This 'reverse Cori cycle' may be advantageous to improve performance by acting on central fatigue and/or alter metabolic regulation $[44,45]$. An animal study had shown that the naked mole-rat can resist hypoxia and acidosis by increasing fructolysis [46]. In our study, dietary fructose intake in the fourth quartile of urban and rural residents was $25.6 \mathrm{~g} /$ day and $16.8 \mathrm{~g} /$ day, respectively, both of which were in relatively low dosages. A series of systematic reviews and meta-analyses have reported that small doses of fructose, or fructose in substitution for glucose or sucrose, may have beneficial effects or not any adverse effects on the components of the MetS [13-16, 34, 47, $48]$. Based on the above points, we suggested that physical activities and relatively low fructose intake may have a beneficial synergistic effect on MetS.

Several limitations should be considered in the present study. First, this cross-sectional study has a natural disadvantage to address causal relationship between dietary fructose intake and MetS. Second, fructose additionally supplied was not distinguished in this study. In previous studies, the intake status of additional fructose and its relationship with metabolic disease were the focus of attention. However, the consumption of added fructose was very low in our study population. Third, the accuracy 
of dietary records was limited for the faint recalling of the participants' and the specificity with which the reported foods were mapped in the dietary recall records. To minimize this situation, all the interviewers had completed a strict training program with detailed methodologies on administration of the dietary questionnaire. Forth, three consecutive 24-h dietary records may not enough to reflect long-term dietary habits. More high-quality cohort studies and randomized controlled trials were still needed to evaluate the association between dietary fructose intake and the risk of MetS.

\section{Conclusions}

To our knowledge, the present study fills a gap by firstly discussing the association between dietary fructose and the odds of having MetS among Chinese residents aged 45 and above. Fruits and fruit products, vegetables and vegetable products were the main food sources, and the dietary fructose intake was relatively low. Under the current dietary fructose intake status, there was no association between dietary fructose intake and the odds of having MetS in both urban and rural residents. Interestingly, there was a significant inverse association between dietary fructose intake and MetS for urban residents who participating in physical activity. Our results indicated that physical activity and relatively low fructose intake may have an advantageous synergistic effect on MetS.

\footnotetext{
Abbreviations

MetS: Metabolic syndrome; CNNHS: China National Nutrition and Health Survey; WC: Waist circumference; BMI: Body mass index; SBP: Systolic blood pressure; DBP: Diastolic blood pressure; FPG: Fasting plasma glucose; TC: Total cholesterol; HDL-C: High-density lipoprotein cholesterol; TG: Triglycerides.
}

\section{Supplementary Information}

The online version contains supplementary material available at https://doi. org/10.1186/s12937-021-00739-9.

Additional file 1: Table S1. Food sources of dietary fructose in urban and rural residents $(\mathrm{g} / \mathrm{d})$. Table $\mathbf{S 2}$. Stratified analysis of the association between dietary fructose intake and the odds of having MetS by physical activity in rural area. Table S3. Stratified analysis of the association between dietary fructose intake and the odds of having MetS by gender. Table S4. Stratified analysis of the association between dietary fructose intake and the odds of having MetS by smoking. Table S5. Stratified analysis of the association between dietary fructose intake and the odds of having MetS by alcohol use.

\section{Acknowledgments}

We acknowledge all the participants in our study and the staffs responsible for producing the China National Nutrition and Health Survey 2010-2012 (CNNHS 2010-2012).

\section{Authors' contributions}

The authors contributions were as follow: Conceptualization, J.Z. and W.Q.; methodology, S.P.; software, S.P.; validation, P.S., C.Y., G.S, and Y.W.; formal analysis, S.P.; investigation, S.P., P.S., C.Y., G.S, and Y.W.; resources, J.Z.; data curation, P.S.; writing —original draft preparation, S.P.; writing — review and editing, J.Z., X.S. and W.Q.; visualization, S.P.; supervision, J.Z.; project administration, W.Q.; funding acquisition, W.Q. The authors read and approved the final manuscript.

\section{Funding}

This work was funded by the Special Funds of Basic Research of Central Public Welfare Institute (No. ZX1902), the National Natural Science Foundation of China (No. 81703216 and No. 31901698) and the Major scientific and technological innovation projects of Shandong Province (No. 2019TSLH0801).

\section{Availability of data and materials}

Not applicable.

\section{Declarations}

Ethics approval and consent to participate

This survey was ethically approved by the Ethical Committee of the National Institute for Nutrition and Food Safety, Chinese Center for Disease Control and Prevention (2013-018). Written informed consent was obtained from all participants.

\section{Consent for publication}

All authors have read and agreed to the published version of the manuscript.

\section{Competing interests}

The authors declare that they have no competing interests.

\section{Author details}

${ }^{1}$ Institute of Grain Quality and Nutrition Research, Academy of National Food and Strategic Reserves Administration, Beijing 100037, People's Republic of China. ${ }^{2}$ National Institute for Nutrition and Health, Chinese Center for Disease Control and Prevention, Beijing 100050, People's Republic of China. ${ }^{3}$ Research and Development center of Shandong Xiwang Sugar Co. Ltd, National Corn Deep Processing Industry Technology Innovation Center, Binzhou, People's Republic of China. ${ }^{4}$ Department of Nutrition and Food Hygiene, School of Public Health, Capital Medical University, Beijing 100069, People's Republic of China.

Received: 12 July 2020 Accepted: 20 September 2021

Published online: 03 October 2021

\section{References}

1. Alberti KG, Zimmet P, Shaw J, Group IDFETFC. The metabolic syndrome--a new worldwide definition. Lancet. 2005;366:1059-62.

2. Saklayen MG. The global epidemic of the metabolic syndrome. Curr Hypertens Rep. 2018;20:12.

3. Marcotte-Chenard A, Deshayes TA, Ghachem A, Brochu M. Prevalence of the metabolic syndrome between 1999 and 2014 in the United States adult population and the impact of the 2007-2008 recession: an NHANES study. Appl Physiol Nutr Metab. 2019;44:861-8.

4. He Y, Li Y, Bai G, Zhang J, Fang Y, Zhao L, et al. Prevalence of metabolic syndrome and individual metabolic abnormalities in China, 2002-2012. Asia Pac J Clin Nutr. 2019;28:621-33.

5. Li Y, Zhao L, Yu D, Wang Z, Ding G. Metabolic syndrome prevalence and its risk factors among adults in China: a nationally representative crosssectional study. PLoS One. 2018;13:e0199293.

6. Hannou SA, Haslam DE, McKeown NM, Herman MA. Fructose metabolism and metabolic disease. J Clin Invest. 2018;128:545-55.

7. Taskinen MR, Packard CJ, Boren J. Dietary fructose and the metabolic syndrome. Nutrients. 2019;11:9.

8. Bray GA, Nielsen SJ, Popkin BM. Consumption of high-fructose corn syrup in beverages may play a role in the epidemic of obesity. Am J Clin Nutr. 2004;79:537-43. 
9. Kelishadi R, Mansourian M, Heidari-Beni M. Association of fructose consumption and components of metabolic syndrome in human studies: a systematic review and meta-analysis. Nutrition. 2014;30:503-10.

10. David Wang D, Sievenpiper JL, de Souza RJ, Cozma Al, Chiavaroli L, Ha $V$, et al. Effect of fructose on postprandial triglycerides: a systematic review and meta-analysis of controlled feeding trials. Atherosclerosis. 2014;232:125-33.

11. Mirtschink P, Jang C, Arany Z, Krek W. Fructose metabolism, cardiometabolic risk, and the epidemic of coronary artery disease. Eur Heart J. 2018;39:2497-505.

12. Choo VL, Viguiliouk E, Blanco Mejia S, Cozma Al, Khan TA, Ha V, et al. Food sources of fructose-containing sugars and glycaemic control: systematic review and meta-analysis of controlled intervention studies. BMJ (Clinical research ed). 2018;363:k4644.

13. Jayalath VH, Sievenpiper JL, de Souza RJ, Ha V, Mirrahimi A, Santaren ID, et al. Total fructose intake and risk of hypertension: a systematic review and meta-analysis of prospective cohorts. J Am Coll Nutr. 2014;33:328-39.

14. Noronha JC, Braunstein CR, Blanco Mejia S, Khan TA, Kendall CWC Wolever TMS, et al. The effect of small doses of fructose and its Epimers on glycemic control: a systematic review and Meta-analysis of controlled feeding trials. Nutrients. 2018;10:1085-903.

15. Evans RA, Frese M, Romero J, Cunningham JH, Mills KE. Chronic fructose substitution for glucose or sucrose in food or beverages has little effect on fasting blood glucose, insulin, or triglycerides: a systematic review and meta-analysis. Am J Clin Nutr. 2017;106:519-29.

16. Evans RA, Frese M, Romero J, Cunningham JH, Mills KE. Fructose replacement of glucose or sucrose in food or beverages lowers postprandial glucose and insulin without raising triglycerides: a systematic review and meta-analysis. Am J Clin Nutr. 2017;106:506-18.

17. Hosseini-Esfahani F, Bahadoran Z, Mirmiran P, Hosseinpour-Niazi S, Hosseinpanah F, Azizi F. Dietary fructose and risk of metabolic syndrome in adults: Tehran Lipid and Glucose study. Nutr Metab (Lond). 2011;8:50.

18. Sun SZ, Anderson GH, Flickinger BD, Williamson-Hughes PS, Empie MW. Fructose and non-fructose sugar intakes in the US population and their associations with indicators of metabolic syndrome. Food Chem Toxicol. 2011:49:2875-82.

19. Pang SQW, Song P, Song G, Wang Y, Zhang J. Intake status and food sources of dietary fructose in Chinese residents aged 45 and above. Food Nutr China. 2020;26 (in press).

20. Pang SJ, Jia SS, Man QQ, Song S, Li YQ, Song PK, et al. Dietary cholesterol in the elderly Chinese population: An analysis of CNHS 2010-2012. Nutrients. 2017:9:934-46.

21. Ainsworth BE, Haskell WL, Whitt MC, Irwin ML, Swartz AM, Strath SJ, et al. Compendium of physical activities: an update of activity codes and MET intensities. Med Sci Sports Exerc. 2000;32:S498-504.

22. U.S. Department of Agriculture. Washington, DC. https://fdc.nal.usda.gov/ download-datasets.html. Accessed: 20 Mar 2020

23. Hou L. Analysis of sugar content of prepackaged food and its application in the assessment of sugar intake in Chinese population [master academic degree thesis]. Beijing: Chinese Center for Disease Control and Prevention; 2017. p. 52-82.

24. Alberti KG, Eckel RH, Grundy SM, Zimmet PZ, Cleeman JI, Donato KA, et al. Harmonizing the metabolic syndrome: a joint interim statement of the international diabetes federation task force on epidemiology and prevention; National Heart, Lung, and Blood Institute; American Heart Association; world heart federation; international atherosclerosis society; and International Association for the Study of obesity. Circulation. 2009;120:1640-5.

25. Chinese Diabetes Society. Guidelines for the prevention and control of type 2 diabetes in China (2017 edition). Chin J Pract Intern Med. 2018;38:292-344.

26. Chiu S, Mulligan K, Schwarz JM. Dietary carbohydrates and fatty liver disease: de novo lipogenesis. Curr Opin Clin Nutr Metab Care. 2018:21:277-82.

27. Rho YH, Zhu Y, Choi HK. The epidemiology of uric acid and fructose. Semin Nephrol. 2011;31:410-9.

28. Caliceti C, Calabria D, Roda A, Cicero AFG. Fructose intake, serum uric acid, and Cardiometabolic disorders: a critical review. Nutrients. 2017;9:395-410.
29. Stanhope KL, Medici V, Bremer AA, Lee V, Lam HD, Nunez MV, et al. A dose-response study of consuming high-fructose corn syrup-sweetened beverages on lipid/lipoprotein risk factors for cardiovascular disease in young adults. Am J Clin Nutr. 2015;101:1144-54.

30. Tappy L, Le KA. Health effects of fructose and fructose-containing caloric sweeteners: where do we stand 10 years after the initial whistle blowings? Curr Diab Rep. 2015;15:54

31. Lambertz J, Weiskirchen S, Landert S, Weiskirchen R. Fructose: a dietary sugar in crosstalk with microbiota contributing to the development and progression of non-alcoholic liver disease. Front Immunol. 2017:8:1159.

32. Oh JH, Alexander LM, Pan M, Schueler KL, Keller MP, Attie AD, et al. Dietary fructose and microbiota-derived short-chain fatty acids promote bacteriophage production in the gut Symbiont lactobacillus reuteri. Cell Host Microbe. 2019;25:273-84 e6.

33. Zhang $Y H$, An T, Zhang RC, Zhou Q, Huang Y, Zhang J. Very high fructose intake increases serum LDL-cholesterol and total cholesterol: a metaanalysis of controlled feeding trials. J Nutr. 2013;143:1391-8.

34. Livesey G, Taylor R. Fructose consumption and consequences for glycation, plasma triacylglycerol, and body weight: meta-analyses and meta-regression models of intervention studies. Am J Clin Nutr. 2008;88:1419-37.

35. Tsilas CS, de Souza RJ, Mejia SB, Mirrahimi A, Cozma Al, Jayalath VH, et al. Relation of total sugars, fructose and sucrose with incident type 2 diabetes: a systematic review and meta-analysis of prospective cohort studies. CMAJ. 2017;189:E711-E20.

36. Sievenpiper JL, de Souza RJ, Mirrahimi A, Yu ME, Carleton AJ, Beyene $J$, et al. Effect of fructose on body weight in controlled feeding trials: a systematic review and meta-analysis. Ann Intern Med. 2012;156:291-304.

37. Choo VL, Viguiliouk E, Blanco Mejia S, Cozma Al, Khan TA, Ha V, et al. Food sources of fructose-containing sugars and glycaemic control: systematic review and meta-analysis of controlled intervention studies. BMJ. 2018;363:k4644-62.

38. Tappy L. Fructose-containing caloric sweeteners as a cause of obesity and metabolic disorders. J Exp Biol. 2018;221.

39. Tappy L. Fructose metabolism and noncommunicable diseases: recent findings and new research perspectives. Curr Opin Clin Nutr Metab Care. 2018;21:214-22.

40. Liu S, Yu D, Guo Q, Wang X, Xu X, Jia F, et al. Consumption status and trend of added sugar containing food among Chinese from 2002 to 2012. Wei Sheng Yan Jiu J Hyg Res. 2016;45:398-401.

41. Guideline: Sugars Intake for Adults and Children. WHO Guidelines Approved by the Guidelines Review Committee. Geneva; 2015.

42. Chiavaroli L, Ha V, de Souza RJ, Kendall CW, Sievenpiper JL. Re. "association of fructose consumption and components of metabolic syndrome in human studies: a systematic review and meta-analysis". Nutrition. 2015;31:419-20.

43. Tappy L, Rosset R. Health outcomes of a high fructose intake: the importance of physical activity. J Physiol. 2019;597:3561-71.

44. Rosset R, Egli L, Lecoultre V. Glucose-fructose ingestion and exercise performance: the gastrointestinal tract and beyond. Eur J Sport Sci. 2017;17:874-84.

45. Tappy L, Rosset R. Fructose metabolism from a functional perspective: implications for athletes. Sports Med. 2017:47:23-32.

46. Park TJ, Reznick J, Peterson BL, Blass G, Omerbasic D, Bennett NC, et al. Fructose-driven glycolysis supports anoxia resistance in the naked molerat. Science. 2017;356:307-11.

47. Braunstein CR, Noronha JC, Khan TA, Mejia SB, Wolever TM, Josse RG, et al, Effect of fructose and its epimers on postprandial carbohydrate metabolism: a systematic review and meta-analysis. Clin Nutr. 2020;39:3308-18.

48. Sievenpiper JL. Fructose: back to the future? Am J Clin Nutr. 2017;106:439-42.

\section{Publisher's Note}

Springer Nature remains neutral with regard to jurisdictional claims in published maps and institutional affiliations. 